\title{
Promoter hypermethylation-mediated inactivation of multiple Slit-Robo pathway genes in cervical cancer progression Gopeshwar Narayan1, Chandra Goparaju1 ${ }^{1}$, Hugo Arias-Pulido², Andreas M Kaufmann ${ }^{3}$, Achim Schneider ${ }^{3}$, Matthias Dürst ${ }^{4}$, Mahesh Mansukhani ${ }^{1}$, Bhavana Pothuri ${ }^{5}$ and Vundavalli V Murty*1,6
}

\begin{abstract}
Address: ${ }^{1}$ Department of Pathology, College of Physicians \& Surgeons of Columbia University, New York, NY, USA, ${ }^{2}$ Department of Tumor Molecular Biology. Instituto Nacional de Cancerología, Bogota, Colombia and Departments of Molecular Genetics and Microbiology, University of New Mexico, Albuquerque, New Mexico, USA, ${ }^{3}$ Charité Universitätsmedizin Berlin, Campus Benjamin Franklin, Klinik für Gynäkologie mit Hochschulambulanz, Hindenburgdamm 30, 12200 Berlin, Germany, ${ }^{4}$ Department of Obstetrics \& Gynecology, Friedrich Schiller University, Jena, Germany, ${ }^{5}$ Gynecologic Oncology, College of Physicians \& Surgeons of Columbia University, New York, NY, USA and ${ }^{6}$ Institute for Cancer Genetics, College of Physicians \& Surgeons of Columbia University, New York, NY 10032, USA

Email: Gopeshwar Narayan - gn110@columbia.edu; Chandra Goparaju-cg2177@columbia.edu; Hugo Arias-Pulido - HArias@salud.unm.edu; Andreas M Kaufmann - andreas.kaufmann@charite.de; Achim Schneider - Achim.Schneider@med.uni-jena.de;

Matthias Dürst - Matthias.Duerst@med.uni-jena.de; Mahesh Mansukhani -mm322@columbia.edu; Bhavana Pothuri - bp2123@columbia.edu; Vundavalli V Murty* - vvm2@columbia.edu

* Corresponding author
\end{abstract}

Published: 15 May 2006

Molecular Cancer 2006, 5:16 doi:10.1186/1476-4598-5-16
Received: 28 February 2006

Accepted: 15 May 2006

This article is available from: http://www.molecular-cancer.com/content/5/1/16

(C) 2006 Narayan et al; licensee BioMed Central Ltd.

This is an Open Access article distributed under the terms of the Creative Commons Attribution License (http://creativecommons.org/licenses/by/2.0), which permits unrestricted use, distribution, and reproduction in any medium, provided the original work is properly cited.

\begin{abstract}
Background: Cervical Cancer (CC) exhibits highly complex genomic alterations. These include hemizygous deletions at 4p 15.3, 10q24, 5q35, 3p 12.3, and IIq24, the chromosomal sites of Slit-Robo pathway genes. However, no candidate tumor suppressor genes at these regions have been identified so far. Slit family of secreted proteins modulates chemokine-induced cell migration of distinct somatic cell types. Slit genes mediate their effect by binding to its receptor Roundabout (Robo). These genes have shown to be inactivated by promoter hypermethylation in a number of human cancers.

Results: To test whether Slit-Robo pathway genes are targets of inactivation at these sites of deletion, we examined promoter hypermethylation of SLITI, SLIT2, SLIT3, ROBOI, and ROBO3 genes in invasive CC and its precursor lesions. We identified a high frequency of promoter hypermethylation in all the Slit-Robo genes resulting in down regulated gene expression in invasive $\mathrm{CC}$, but the inhibitors of DNA methylation and histone deacetylases (HDACs) in CC cell lines failed to effectively reactivate the down-regulated expression. These results suggest a complex mechanism of inactivation in the Slit-Robo pathway in CC. By analysis of cervical precancerous lesions, we further show that promoter hypermethylation of Slit-Robo pathway occurs early in tumor progression.

Conclusion: Taken together, these findings suggest that epigenetic alterations of Slit-Robo pathway genes (i) play a role in CC development, (ii) further delineation of molecular basis of promoter methylationmediated gene regulation provides a potential basis for epigenetic-based therapy in advanced stage CC, and (iii) form epigenetic signatures to identify precancerous lesions at risk to progression.
\end{abstract}




\section{Background}

Metastasis and treatment failure is a significant cause of death in invasive Cervical Cancer (CC). Although combination chemotherapy with cisplatin as a primary agent has been commonly used in $\mathrm{CC}$, the overall survival rate did not significantly improve [1]. Despite the obvious role of invasion and metastasis in treatment failure of $\mathrm{CC}$, the molecular mechanisms remain poorly understood. A wide number of genes implicated in metastasis that play role in the migration of tumor cells have been identified [2]. In particular, chemokines that contribute to tumor cell invasion and growth plays a major role in metastasis [3]. Recently, a regulatory molecular pathway involving proteins of Slit-Robo genes has been shown to modulate chemokine-induced leukocyte migration $[4,5]$. The Slit family of secreted proteins has been identified as molecular guidance cues including cell migration. Slit genes mediate their effect by binding to its receptor Roundabout (Robo) and by an intracellular signal transduction pathway that includes the Abelson kinase, the Enabled protein, GTPase activating proteins, and the Rho family of small GTPases [6]. Interestingly, Slit also appears to use Roundabout to control leukocyte chemotaxis besides neuronal migration, suggesting a fundamental conservation of mechanisms guiding the migration of distinct types of somatic cells [6].

Recent studies show that Slit-Robo pathway genes are inactivated by promoter hypermethylation in a number of tumor types [7-11]. The chromosomal regions that map Slit-Robo pathway genes have been shown to be frequently deleted in CC $[12,13]$. We hypothesize that the Slit-Robo pathway genes may be targets of inactivation by a combination of deletion and epigenetic mechanisms in CC. In order to test this, we have investigated five genes in this pathway for epigenetic changes during CC progression.

\section{Results and discussion}

The chromosomal bands 4p15.3 (SLIT2), 10q24 (SLIT1), $5 \mathrm{q} 35$ (SLIT3), 3p12.3 (ROBO1 and ROBO2), and $11 \mathrm{q} 24.2$ ( $R O B O 3$ and $R O B O 4$ ) that Slit-Robo pathway genes are located have been previously shown to be frequent targets of LOH in CC [12,13]. To identify if the SlitRobo pathway genes are targets of chromosomal deletions, we chose to examine loss of heterozygosity (LOH) in the vicinity of SLIT2 at 4p15.3 and ROBO1/ROBO2 at 3 p12.3 regions, the two most critical genes in the pathway. We performed LOH in 30 primary tumors using STS markers (D4S1593, D4S1562, D4S2946, D4S1525, D3S1542, D3S3681, D3S3031, and D3S3508) mapped close to these genes. This analysis found hemizygous deletions of one or more of these loci in only $9 \%$ and $10 \%$ of CC at 4p15.3 and 3p12.3, respectively (data not shown). This data, thus, suggests that genomic regions spanning
SLIT2 and ROBO1/ROBO2 genes are not frequent targets of $\mathrm{LOH}$ in CC. Because of the recent reports of promoter hypermethylation of SLIT2 and ROBO1 genes in multiple tumor types $[7-9,11,14]$, we reasoned that this family of genes may be targets of epigenetic inactivation in CC. To test this hypothesis, we examined the status of hypermethylation of SLIT1, SLIT2, SLIT3, ROBO1, and ROBO3 genes that harbor $\mathrm{CpG}$ islands in their promoters in CC progression.

\section{Slit-Robo pathway genes are concomitantly hypermethylated in invasive $C C$}

To evaluate the methylation status of SLIT1, SLIT2, SLIT3, $R O B O 1$, and $R O B O 3$ gene promoters, we employed the methylation-specific PCR (MSP) method that qualitatively assess the presence or absence of hypermethylation of a small number of CpG sites within the promoter [15]. Primers used for this analysis are shown in Table 1. Such an analysis on 51 specimens obtained from normal cervical epithelia did not show any evidence of promoter hypermethylation in SLIT1, SLIT2, SLIT3, ROBO1, and $\mathrm{ROBO} 3$ genes. These data, thus, suggest that Slit-Robo pathway genes are in unmethylated state in normal squamous epithelium of cervix. However, our analysis of 119 DNAs derived from CC (9 cell lines and 110 primary tumors) identified a high frequency of promoter hypermethylation of these genes ranging between 35.6-63.9\% tumors (Figures 1 and 2). SLIT2 was the most frequently (76 of 119 tumors; 63.9\%) methylated gene. Promoter hypermethylation of SLIT1 in 52.9\% (63 of 119 tumors), SLIT3 in $49.2 \%$ (58 of 118 tumors), ROBO1 in $46.2 \%$ (55 of 119 tumors), and ROBO3 in $35.6 \%$ (42 of 118 tumors) cases was found.

Promoter hypermethylation of SLIT2 ranging in frequency between 25-72\% has been reported in a broad spectrum of tumors such as colon, glioma, lung, breast, renal cell cancer, Wilms tumor, and neuroblastoma $[8,9,11,16]$. Promoter hypermethylation of other SlitRobo pathway genes has not been extensively studied in cancer. SLIT3 gene promoter hypermethylation ranging from $7-41 \%$ has been shown in tumors arising from carcinomas of lung, breast, colon, and glioma [16]. Promoter hypermethylation of SLIT1 gene reported to be present in $10 \%$ of gliomas [16]. The ROBO1 gene promoter methylation has been found in $4-19 \%$ in lung, breast, and renal cell carcinomas [7]. ROBO3 gene promoter methylation has not been reported in cancer so far. In the present study, we identified promoter hypermethylation in all five Slit-Robo pathway genes examined and the observed frequency of methylation is the highest in any tumor type reported thus far. One or more genes in this pathway exhibited promoter hypermethylation in $85 \%$ of CC cases suggesting a major role for the Slit-Robo pathway in this cancer. Three or more genes showed promoter hyper- 
Table I: Primers used for MSP, RT-PCR, and cloning and sequencing.

\begin{tabular}{|c|c|c|}
\hline \multicolumn{3}{|l|}{ MSP primers: } \\
\hline SLITI-MF2 & 5'-TtcgTtcgcgagTTagacg-3' & $19 \mathrm{bp}$ \\
\hline SLITI-MR2 & 5'-aAAcgccgtcgcttAAaAA-3' & $19 \mathrm{bp}$ \\
\hline SLITI-UF2 & 5'-TgggTttgTgTgTggTgTTT-3' & $20 \mathrm{bp}$ \\
\hline SLITI-UR2 & 5'-ttttcctcctcAcaAcaAtcaA-3' & $22 \mathrm{bp}$ \\
\hline SLIT2-MF & 5'-gggaggcgggattgTTTag-3' & $19 \mathrm{bp}$ \\
\hline SLIT2-MR & 5'-catAAcgcgcgAAAAtAcac-3' & $20 \mathrm{bp}$ \\
\hline SLIT2-UF & 5'-gTgggaggTgggattgTTTa-3' & $20 \mathrm{bp}$ \\
\hline SLIT2-UR & 5'-AcctctccctcAccctcAac-3' & $20 \mathrm{bp}$ \\
\hline SLIT3-MF & 5'-ggtttcgtcgatggagttgt-3' & $20 \mathrm{bp}$ \\
\hline SLIT3-MR & 5'-aaacgcgtaaaacccgaaa-3' & $19 \mathrm{bp}$ \\
\hline SLIT3-UF & 5'-TGTGggTTagTGgggTTagg-3' & $20 \mathrm{bp}$ \\
\hline SLIT3-UR & 5'-cacaaacaaaacaaaacactcca-3' & $23 \mathrm{bp}$ \\
\hline ROBOI-MF2 & 5'-cggcggcgatagTagTTaaa-3' & $20 \mathrm{bp}$ \\
\hline ROBOI-MR2 & 5'-cgAAActAAAAAcgcccaAa-3' & $20 \mathrm{bp}$ \\
\hline ROBOI-MF3 & 5'-cggcgtgcgTTTTTa Taatg-3' & $20 \mathrm{bp}$ \\
\hline ROBOI-MR3 & 5'-gccAcgAAtAAcccgctAct-3' & $20 \mathrm{bp}$ \\
\hline ROBOI-UF & 5'-TggTggTaaagttggggtgt- 3 ' & $20 \mathrm{bp}$ \\
\hline ROBOI-UR & 5'-ccAaAcccttcctccAAaAc-3' & $20 \mathrm{bp}$ \\
\hline ROBO3-MF & 5'-gcgggaTtTtTagTcggTTT-3' & $20 \mathrm{bp}$ \\
\hline ROBO3-MR & 5'-gAcctctccgcaAActAAcg-3' & $20 \mathrm{bp}$ \\
\hline ROBO3-UF & 5'-TggTgggaTtTtTagTTggTTT-3' & $22 \mathrm{bp}$ \\
\hline ROBO3-UR & 5'-ccAcaActtccccAcAAcAc-3' & $20 \mathrm{bp}$ \\
\hline \multicolumn{3}{|c|}{ RT-PCR primers: } \\
\hline SLITI-F & 5'-ctggaactcaatggcaacaa-3' & $20 \mathrm{bp}$ \\
\hline SLITI-R & $5^{\prime}$-acaaagcctggttgttctgg- 3 ' & $20 \mathrm{bp}$ \\
\hline SLIT2-F & $5^{\prime}$-tcagctgtttcctgagttgc-3' & $20 \mathrm{bp}$ \\
\hline SLIT2-R & 5'-tggttgaaacttgccacaga-3' & $20 \mathrm{bp}$ \\
\hline SLIT3-F & 5'-gcgcctgaacaagaataagc-3' & $20 \mathrm{bp}$ \\
\hline SLIT3-R & 5 -ggatgcgactgatgttgttg-3' & $20 \mathrm{bp}$ \\
\hline ROBOI-FI & $5^{\prime}$-tgtttctggcccagcttatt-3' & $20 \mathrm{bp}$ \\
\hline ROBOI-RI & 5'-gtgttcaacaatgcgaggtg-3' & $20 \mathrm{bp}$ \\
\hline ROBOI-F2 & 5'-aaatatggtgggcaaagctg-3' & $20 \mathrm{bp}$ \\
\hline ROBOI-R2 & $5^{\prime}$-ctggatgactgtggtggttg-3' & $20 \mathrm{bp}$ \\
\hline $\mathrm{ROBO} 3-\mathrm{F}$ & 5'-gcagtcctccgtgatgattt-3' & $20 \mathrm{bp}$ \\
\hline ROBO3-R & 5'-ttggaggctacgcacacata-3' & $20 \mathrm{bp}$ \\
\hline \multicolumn{3}{|c|}{ Cloning Primers: } \\
\hline SLIT2-cl-F & 5'-gaattTaaagTTtgggaaaaagttg-3' & 24 bp \\
\hline SLIT2-cl-R & 5'-cttccaacaactactaaaatacaaaaa-3' & $27 \mathrm{bp}$ \\
\hline SLIT2-Cl-F3 & 5'-agtgTtgaTtagtggatatttTtgTT-3' & $26 \mathrm{bp}$ \\
\hline SLIT2-cl-R3 & 5'-tcttctAtctcccaaAAatAaactt-3' & $25 \mathrm{bp}$ \\
\hline
\end{tabular}

Nucleotides shown in upper case represent converted bases; MF and $M R$, methylation-specific forward and reverse primers; UF and UR, unmethylated forward and reverse primers; $F$ and $R$, forward and reverse primers; $\mathrm{cl}-\mathrm{F}$ and $\mathrm{cl}-\mathrm{R}$, cloning forward and reverse primers

methylation in $53 \%$ of the tumors studied. Among the 101 tumors with promoter hypermethylation, $16(13 \%)$ showed methylation of all five genes (Fig. $2 \mathrm{~A}$ and $2 \mathrm{~B}$ ). To further confirm MSP results and to assess the extent of methylation of $\mathrm{CpG}$ sites, we performed sequence analysis on representative tumors either by direct sequencing of PCR products or sequencing followed by cloning PCR products. We found consistent results by both methods in all tested cases (Fig. 2C). Furthermore, the sequencing data provided a qualitative estimate of methylation of $\mathrm{CpG}$ sites in all five genes examined. The extent of $\mathrm{CpG}$ methylation varied among the genes tested in invasive cancer and precancerous lesions. SLIT1 gene showed 87.5-93.8\% methylated CpG sites, SLIT2 exhibited 100\% CpG site methylation, SLIT3 showed 40.7-100\%, ROBO1 showed 41.7-100\%, and ROBO3 showed 87.5\% CpG site methylation. We did not notice any substantial differences in the number of CpG sites methylated between invasive cancer and precancerous lesions. Thus, this data provide evidence for Slit-Robo pathway genes as targets of promoter hypermethylation in CC and the concomitant methylation of multiple genes further suggest a complex mechanism of inactivation of this pathway in CC tumorigenesis.

In order to further examine the role of Slit-Robo genes in $\mathrm{CC}$, we performed a correlative analysis of hypermethylation with clinico-pathologic features such as age, tumor stage and size of the tumor, clinical outcome, and HPV type in primary tumors. No significant differences were found when individual genes were examined (data not shown). No significant differences in promoter hypermethylation between cell lines and primary tumors were found (data not shown). However, we found that advance stage tumors (stages III and IV) exhibit a significantly ( $\mathrm{p}<$ 0.025 ) higher frequency of promoter methylation in 2 or more Slit-Robo family genes compared to early stage (stages I and II) tumors (Fig. 2D). These data therefore suggest that concomitant promoter hypermethylation and inactivation of multiple Slit-Robo pathway genes play a role in progression of CC.

The presence of concordant high frequency of promoter hypermethylation of Slit-Robo pathway genes in CC is reminiscent of the CpG Island Methylator Phenotype (CIMP) in cancer [17]. The CIMP phenotype can be caused by exposure to epimutagens, which potentially target gene-specific methylation in a cancer-specific manner $[18,19]$. Infection of high-risk human papillomavirus (HPV) is known to be primary cause of CC [20]. In the present study, we did not find any significant correlation between methylation frequency and various HPV types in CC. However, a controlled study comprising a large number of HPV-negative tumors is required to completely rule out the role for HPV in Slit-Robo pathway gene methylation. Although the causes of CIMP remain poorly understood, a significant correlation of DNA methyltransferases (DNMTs) expression with DNA hypermethylation of multiple CpG islands has been shown [21]. DNMTs have been also shown to be generally over express in cancer and play a role in aberrant DNA methylation $[17,22]$. To examine the role of DNMT expression in Slit-Robo pathway gene methylation, we examined the expression levels of DNMT1, DNMT3a, and DNMT3b by semi-quantitative RT-PCR analysis. We identified over expression of all three tested DNMTs in CC. DNMT1 over expression 


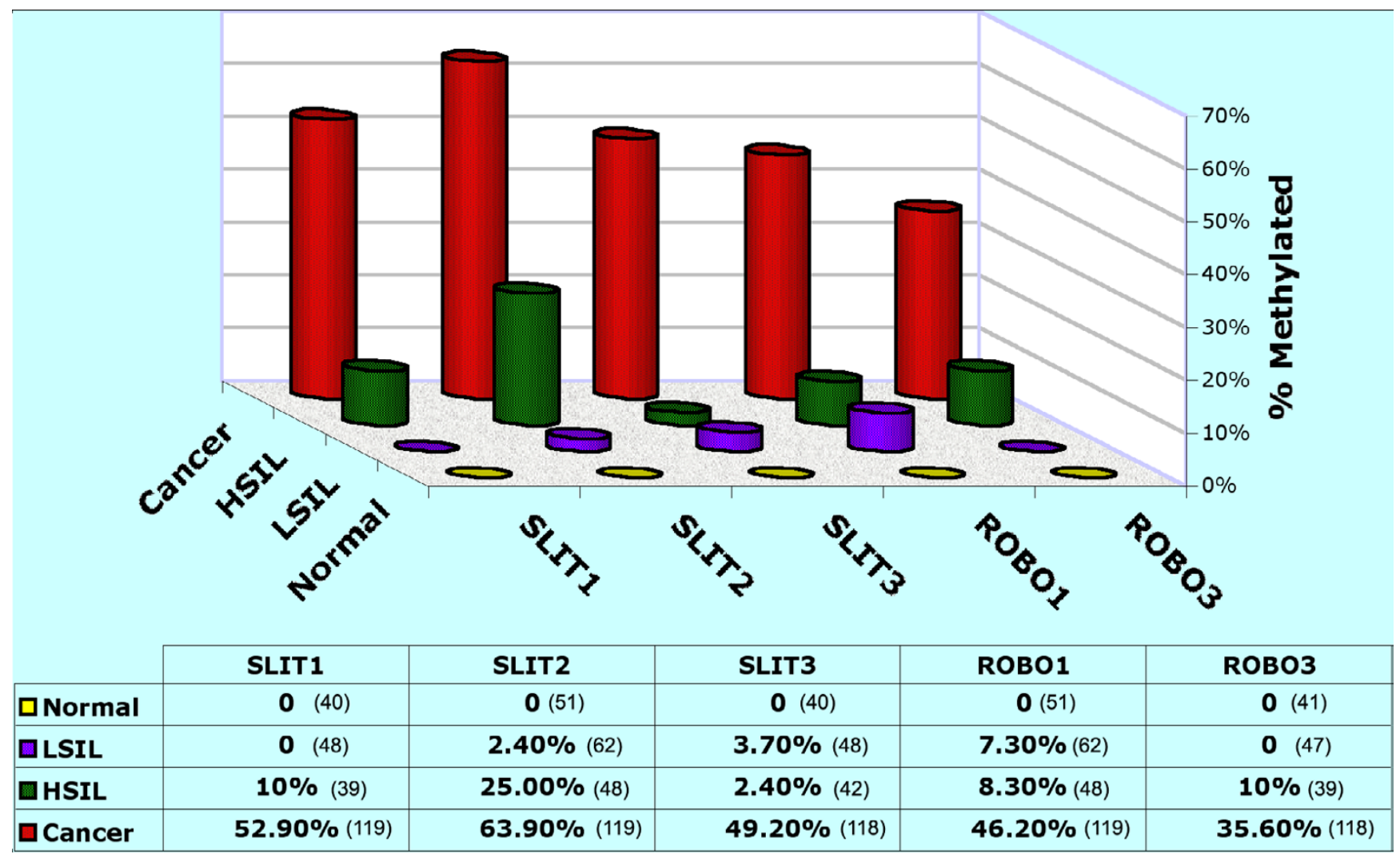

Figure I

Frequency of promoter hypermethylation of Slit-Robo pathway genes in cervical cancer progression. High molecular weight DNA isolated from pap smears and tissue sections was converted by sodium bisulphite [I5]. MS-PCR was performed on converted DNA using primers specific to methylated and umethylated templates of each gene (Table I). PCR products were separated on $2 \%$ agarose gels and visualized after ethidium bromide staining. Promoter methylation was scored on gels in the presence of positive and negative controls in each experiment. LSIL, low-grade squamous intraepithelial lesion; HSIL, highgrade squamous intraepithelial lesion. The total number of specimens analyzed in each type of tissue and gene are shown in parenthesis in the table below.

was found in all CC cases (100\%), whereas the DNMT3a $(73.7 \%)$ and DNMT3b (78.9\%) genes were over expressed to a lesser extent in CC cases (Fig. 4). However, this over expression of DNMTs showed no significant correlation with promoter hypermethylation of Slit-Robo pathway genes (data not shown), and therefore no relationship between these molecular alterations could be established.

Slit2 inhibits chemotaxis and chemoinvasion by downmodulating down-stream signaling molecules CXCR4/ CXCL12 and CXCL12-induced phosphatidylinositol 3 kinase [23] and Slit-2 protein can inhibit the migration of endothelial cells lacking Slit-2 [5]. Therefore, the epigenetic silencing of multiple Slit-Robo pathway genes may play a role in invasive potential of CC cells. Based on the functions of Slit-Robo family genes and our observations raise a number of questions: $\mathrm{i}$ ) what is the role of inactivation of both receptor and ligand in CC tumorigenesis? ii) Is there an upstream regulator of promoter methylation of
Slit-Robo pathway genes in CC? iii) Are there any downstream effectors of Slit-Robo methylation that affect invasion and migration of CC cells?

Promoter hypermethylation of Slit-Robo pathway genes is an early event in tumor progression

To identify the role of promoter hypermethylation of SlitRobo genes in CC progression, we studied DNA obtained from 110 cytological smears diagnosed as low-grade squamous intraepithelial lesions (LSIL) in 62 and high-grade SIL (HSIL) in 48 cases by MSP. We found evidence of promoter hypermethylation in at least one gene in 11 of 62 (17.7\%) LSIL and 15 of 48 (31.3\%) HSIL, which suggests that Silt-Robo pathway genes are methylated early in CC progression. Among the LSILs, a low frequency of hypermethylation occurs in SLIT2, SLIT3, ROBO1, whereas SLIT1 and ROBO3 showed no methylation. While the promoter hypermethylation of SLIT1, SLIT3, ROBO1, and $\mathrm{ROBO} 3$ genes were low in HSIL, the SLIT2 gene showed 

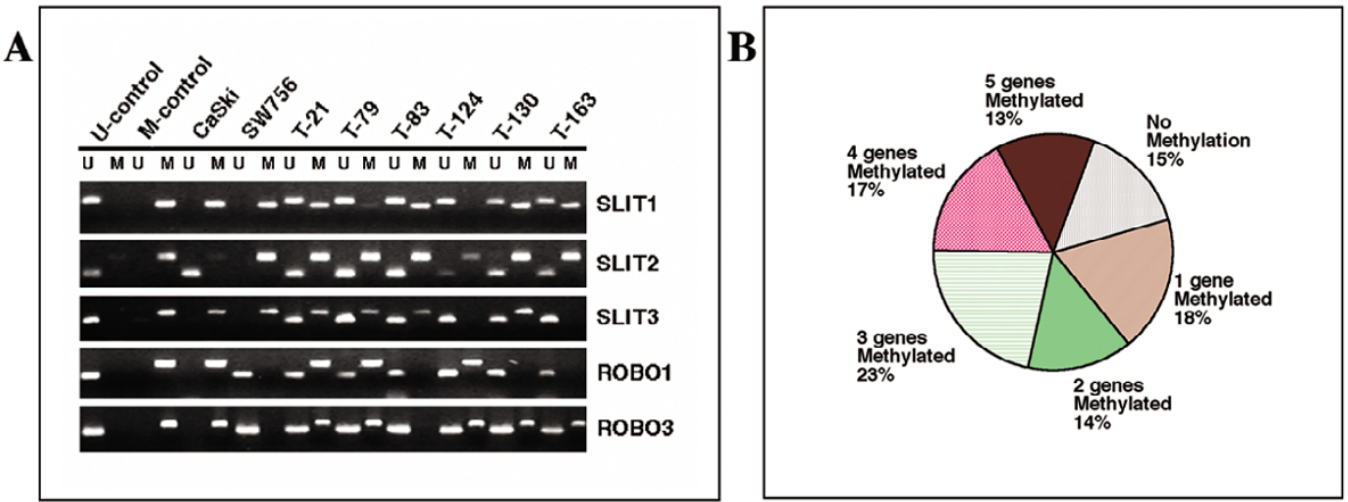

C

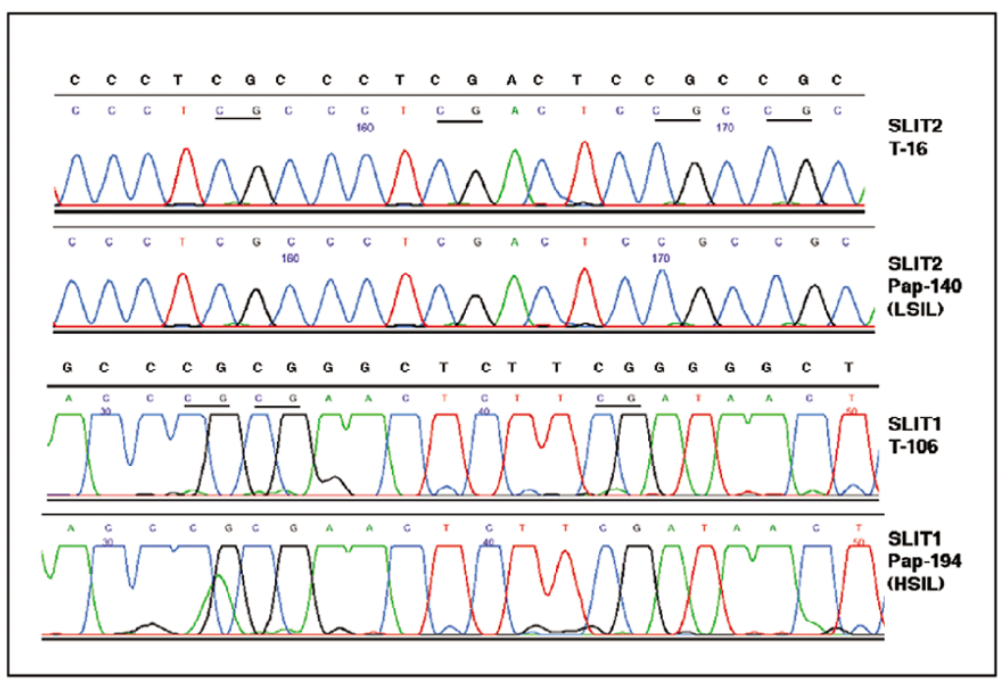

D

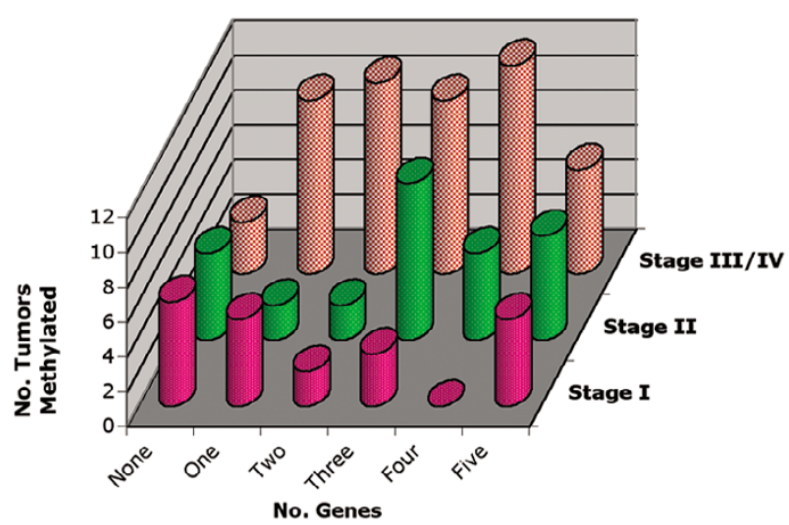

Figure 2

Analysis of methylation of Slit-Robo pathway genes in cervical cancer cell lines and primary tumors. A. MSP analysis. U, unmethylated; M, methylated. T, tumor. B. Concomitant hypermethylation of more than one Slit-Robo genes in primary cervical cancer. Frequency of number of genes methylated is shown. C. Sequence analysis of MSP products of SLITI and SLIT2 genes. SLIT2 sequences were derived from cloning of PCR products and SLITI was direct sequencing of MSP products. T, tumor; pap, cytologic smear. CpG sites are underlined. Unconverted sequence is shown above chromatogram for each gene. $\mathbf{D}$. Number of Slit-Robo genes methylated in various stages of invasive cervical cancer. 

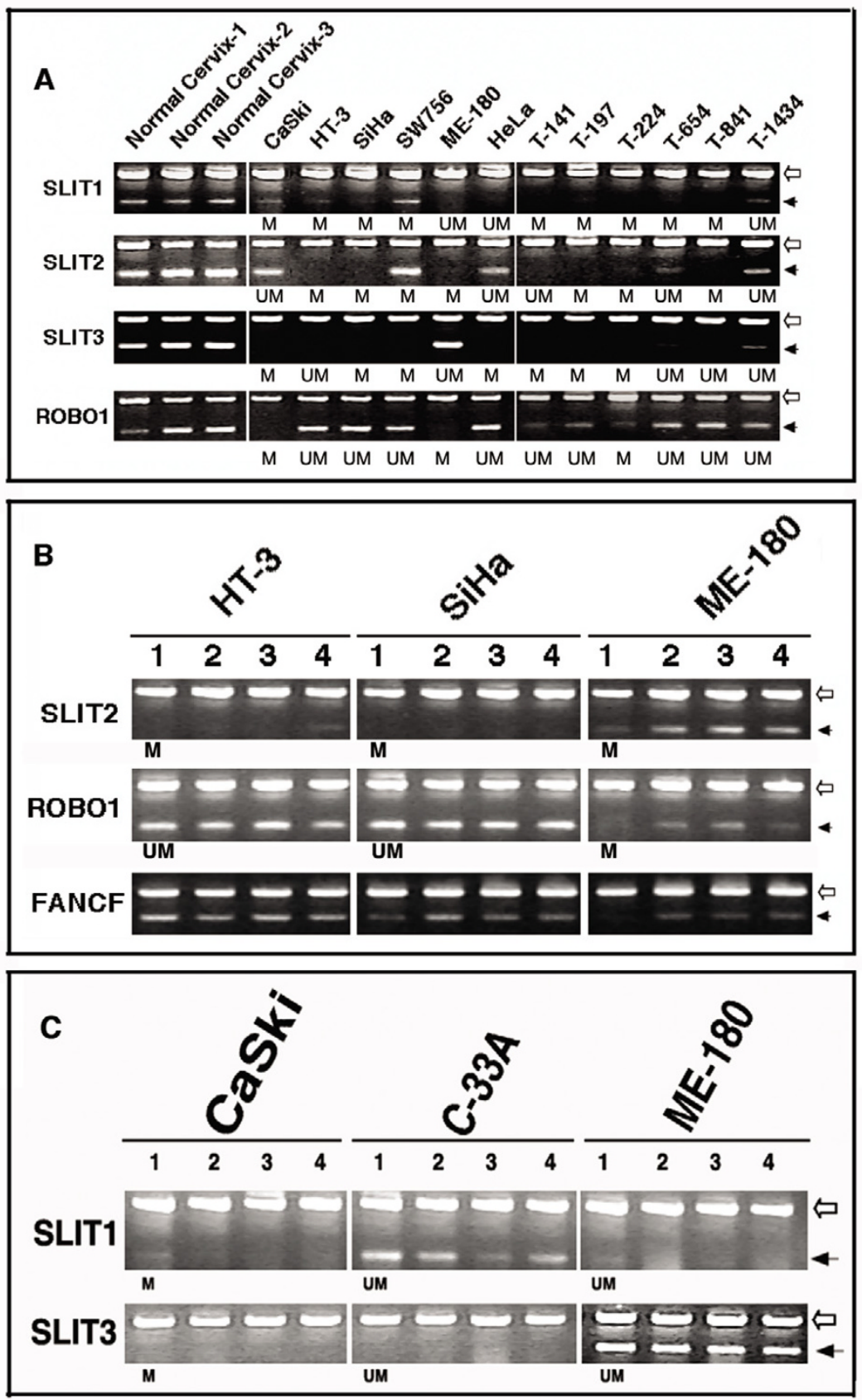

Figure 3

Analysis of Slit-Robo pathway gene expression by RT-PCR in cervical cancer cell lines and primary tumors. A. Expression of SLITI, SLIT2, SLIT3, and ROBOI genes. Note the high-levels of expression in normal cervix, complete loss or down-regulated expression in the cell lines (CaSki, HT-3, SiHa, SW756, ME-180, and HeLa) and primary tumors (shown by prefix "T" for tumor). B-C. Effect of demethylation and acetylation on SLIT2, ROBOI, SLITI, and SLIT3 genes. FANCF gene is shown as a control for reactivation of expression in $\mathrm{SiHa}$ and $\mathrm{ME}-\mathrm{I} 80$ in panel B [3I]. Lanes I, untreated; 2, 5-aza-CdR-treated (5 or I0 $\mu \mathrm{M}$ for 5 days); 3, TSA treated ( 100 nM for the last 24 hours); 4, 5-aza-CdR and TSA treated. Note that SLIT2 promoters were methylated in all three-cell lines but only ME- 180 showed reactivation, while HT-3 showed minimal reactivation only in combined 5-aza-CdR and TSA treated cells but not with other treatments. SiHa failed to reactivate. For ROBOI gene, ME-I80 had methylated promoter and showed reactivated expression with all treatments. No reactivation of SLITI and SLIT3 genes in promoter methylated CaSki cell line was found. Beta actin (empty arrow) used as an internal control; Filled arrows indicate specific genes used for RT-PCR. Promoter methylation status of each gene is shown below the panels. 


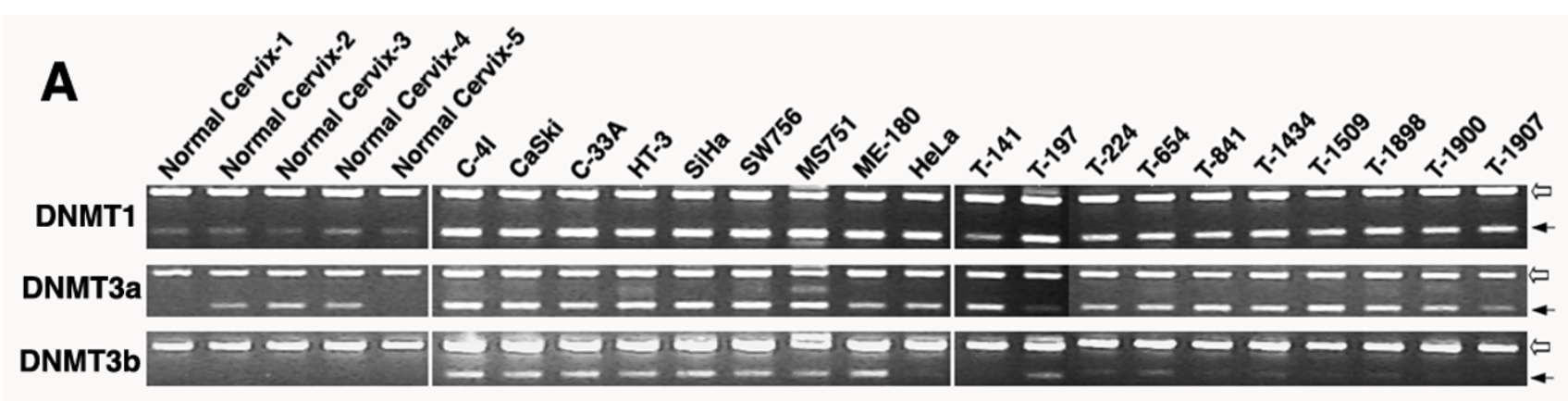

B

\begin{tabular}{|l|l|}
\hline Gene & No. of tumor over expressed (\%) \\
\hline DNMT1 & $19 / 19(100 \%)$ \\
\hline DNMT3a & $14 / 19(73.7 \%)$ \\
\hline DNMT3b & $15 / 19(78.9 \%)$ \\
\hline
\end{tabular}

\section{Figure 4}

Analysis of expression of DNMT genes in normal cervix, cervical cancer cell lines, and primary tumors. A. Multiplex RT-PCR analysis of DNMTI, DNMT3a, and DNMT3b genes. Prefix "T" indicates primary tumor. Beta actin (empty arrow) used as an internal control; Filled arrows indicate specific genes used for RT-PCR. B. Table showing the frequency of over expression of each of the genes based on semi-quantitative analysis.

higher frequency of hypermethylation in 12 of $48(25 \%)$ cases (Fig. 1). This data suggest that SLIT2 inactivation is an early and a primary event, while the methylation of the other genes in the pathway occur later in the progression. The natural history of cervical precancerous lesions varies with approximately $1 \%$ of low-grade and $15 \%$ of highgrade Cervical Intraepithelial Neoplastic lesions progress to invasive cancer [24], and therefore, the epigenetic changes documented here may form potential signatures to identify precancerous lesions at high-risk to progress to invasive cancer. However, analysis of a larger cohort of precancerous and cancerous lesions is needed to validate such a hypothesis.

Down regulated expression of Slit-Robo pathway genes in relation to promoter hypermethylation and inefficient reactivation after exposure to inhibitors of methylation and histone deacetylases

Although the Slit-Robo family proteins primarily express in the developing nervous system, they also widely express outside the nervous system in adult tissues suggesting roles outside the developing embryo [25]. Consistent to this, we found that all three Slit genes and ROBO1 are ubiquitously expressed in normal cervical tissues (Fig. 3A). However, no detectable expression of $\mathrm{ROBO} 3$ in normal cervix or in CC cell lines by RT-PCR was found and thus this gene was not studied for expression. To further test the role of promoter hypermethyation of SLIT1, SLIT2, SLIT3, and ROBO1 genes in CC, we studied the expression by semi-quantitative RT-PCR analyses in nine CC cell lines and 10 primary tumors. A complete loss of or down regulated expression was found in the majority of cases with promoter hypermethylation of SLIT2 (9 of $11 ; 81.8 \%$ ), SLIT1 ( 8 of $11 ; 72.7 \%$ ), SLIT3 (11 of 11 ; $100 \%$ ), and ROBO1 ( 6 of $7 ; 87.5 \%$ ) genes compared to normal cervices (Fig. 3A). Overall, the down-regulated expression correlate with promoter hypermethylation and these results suggest that epigenetic promoter methylation play a role in inactivating Slit-Robo pathway genes in CC.

DNA hypermethylation-mediated gene silencing is closely associated with histone modifications such as methyl-H3K9. In this regard, the DNA demethylating agent 5-aza-2'deoxycytidine (5-aza-CdR) and the HDAC inhibitor TSA reactivates expression of epigenetically silenced genes [26]. We examined the expression of these genes in cell lines after treatment with 5-aza-CdR, TSA, or both to test if the promoter hypermethylation-mediated down modulated gene expression can be reversed by demethylation and inhibition of HDACs. Of the five cell lines with SLIT2 promoter hypermethylation two (C-4I and SiHa) failed to induce reactivation after 5 -aza-CdR or TSA treatments. Two other cell lines (SW756 and HT-3) showed minimal reactivation after treatment with one or the other drug. ME-180 is the only cell line that showed reactivation comparable to normal expression (Fig. 3B). None of the four cell lines (CaSki, HT-3, SW756, and SiHa) with SLIT1 methylated promoters showed reactivation (Fig. 3C). The SLIT3 gene failed to reactivate in two (CaSki and SiHa) of four methylated cell lines. The other two (SW756 and 


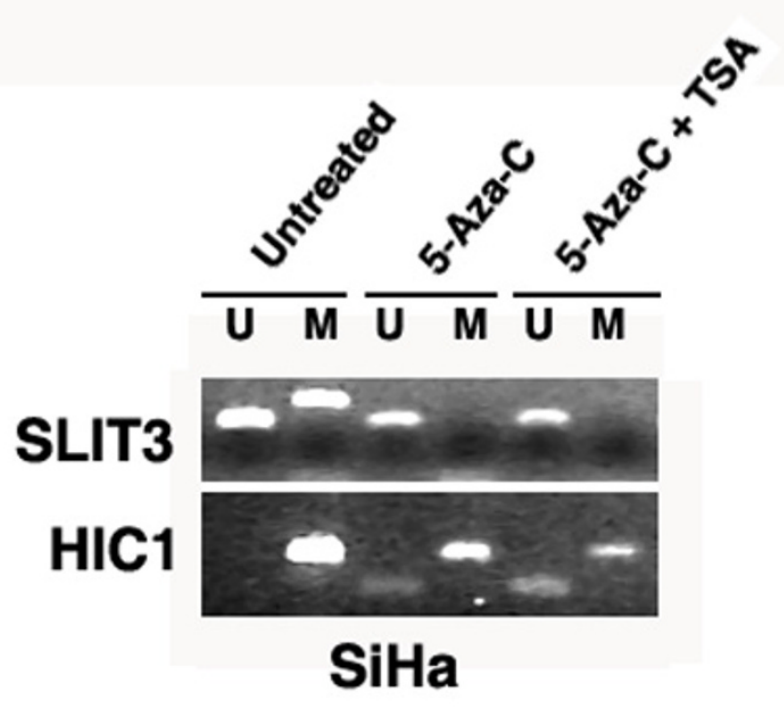

\section{Figure 5}

Effect of inhibition of DNA methylation by 5 -aza-CdR and TSA-treatment on SLIT3 promoter in SiHa cell line. Biallelically methylated $\mathrm{HICl}$ gene was used as control [29]. U, unmethylated primer; $M$, methylated primer; Note the absence of methylated allele after treatment with 5-aza-CdR, and 5-aza-CdR+TSA of SLIT3 gene (top panel). Note the decreased intensity of methylated allele and reappearance of unmethylated allele of $\mathrm{HICl}$ after 5-aza-CdR, and 5-azaCdR+TSA treatments (bottom panel).

HeLa) cell lines showed only minimal reactivation after 5aza-CdR treatment but not with TSA (Fig. 3C). The ROBO1 gene showed reactivated expression only in one of two (CaSki and ME-180) methylated cell lines (Fig. 3B). Thus, these data indicate that the demethylation of promoters of Slit-Robo pathway genes do not effectively reactivate gene expression. This failure or inappropriate reactivation of gene expression after 5-aza-CdR or HDAC treatments can be due to number of experimental problems such as aged buffered 5-aza-CdR or inadequate periods and concentrations of drug exposure. We ruled out these possibilities by using fresh 5-aza-CdR, varying drug concentrations ( $5 \mu \mathrm{g}$ and $10 \mu \mathrm{g})$ and period of exposure (5 to 10 days), and in triplicate assays. The effect of drug treatment on demethylation was also confirmed by MSP in which the amplification of methylated allele was either completely absent or highly decreased and a reappearance of unmethylated alleles in a biallelically methylated cell lines (Fig. 5). Our cloning and sequencing analysis of 5aza-CdR treated and bisulphate-converted DNAs also showed a rate of $33-65 \%$ demethylated CpG sites of SLIT2 gene (data not shown).

Although the role of demethylating drugs that target transcriptional repressor complexes in tumors remains poorly understood, it is known that the interaction of receptors and their cognate ligands is critical in mediating gene activation[27]. The present observation of inefficient reactivation of Slit-Robo pathway genes after treatment with 5aza-CdR in CC may be due to concomitant promoter hypermethylation of receptors and ligands resulting in failure of ligand-receptor interactions. Also, it has been shown that DNMT inhibitor 5-aza-CdR treatment has been shown to induce reactivation of only a limited number of genes in a tissue and pathway specific manner [28]. Based on this, Karpf et al. proposed that the mechanism of transcriptional regulation of 5-aza-CdR-mediated gene reactivation requires both a reversal of hypermethylation and the presence of trans-factors that mediate the activation of hypomethylated target promoters. In the present study, we show that the reversal of promoter hypermethylation of Slit-Robo pathway genes could be achieved after 5-aza-CdR treatment. However, we were unable to simultaneously achieve the gene re-activation. These data, thus, suggest that the promoter methylationmediated activation of Slit-Robo pathway also requires critical upstream transcriptional regulators. The identification of such promoter specific transcriptional activators of Slit-Robo genes is essential to understand the role of hypemethylation of this pathway and to fully realize the scope of 5-aza-CdR-mediated gene activation. Whether such a phenomenon of Slit-Robo pathway regulation is restricted to CC or exists in other tumor types remains unknown.

\section{Conclusion}

The present study identified a high frequency of promoter hypermethylation of Slit-Robo pathway genes in invasive $\mathrm{CC}$ and the associated precancerous lesions. These data, thus, suggest that Slit-Robo pathway inactivation significantly contribute to the pathogenesis of CC. These results provide new insights into possible pathogenic mechanisms in CC transformation and may have clinical implications in designing epigenetic-based therapy in the treatment of advanced stage CC. The occurrence of promoter hypermethylation in precancerous lesions and their association with progression to invasive CC suggests that these alterations may serve as biomarkers of risk prediction in progression.

\section{Methods}

\section{Patients, tumor tissues, and cell lines}

A total of 119 samples of DNA derived from 110 at-diagnosis tumor biopsies from invasive CC and nine cell lines were used. The tumor biopsies were ascertained from patients evaluated at the Instituto Nacional de Cancerologia (Santa Fe de Bogota, Colombia), Department of Obstetrics and Gynecology of Friedrich Schiller University (Jena, Germany), and Columbia University Medical Center (New York) after appropriate informed consent 
and approval of protocols by institutional review boards. The primary tumors were clinically classified as FIGO stage IB (27 tumors), IIB (31 tumors), IIIB (47 tumors), and IV (5 tumors). Histologically, 105 tumors (Age range 27-85 yrs; mean 49 yrs) were classified as squamous cell carcinoma (SCC) and five as adenocarcinoma (AC). Clinical information was collected from most patients as described [29]. Cervical swabs from 151 cases were collected in phosphate buffered saline from patients attending the Gynecologic Oncology Clinic at Columbia University Medical Center, New York, after appropriate informed consent. Forty-one of these were diagnosed cytologically as normal (Age range 16-74 yrs; mean 35.4 yrs) with no previous history of SIL, 62 as low-grade SIL (Age range 14-66 yrs; mean 29.7 yrs) and 48 as highgrade SIL (Age range 19-75 yrs; mean 39.2 yrs). In addition, we utilized 10 normal (Age range 41-64 yrs; mean 51.1 yrs) cervical epithelial cell preparations derived from hysterectomy specimens as normal controls. The CC cell lines HeLa, SiHa, SW756, C-4I, CaSki, C-33A, HT-3, MS751 and ME-180 were obtained from the American Type Culture Collection (Manassas, VA), and were grown according to the supplier's recommendations. DNA and/ or RNA were isolated from frozen tumor tissues or cultured cells by standard methods. RNA was obtained from 10-micron sections with H\&E staining of adjacent sections to evaluate tumor content. Specimens that contained more than $70 \%$ tumor cells were used for RNA preparation.

Loss of Heterozygosity (LOH) analysis and HPV detection LOH analysis was performed using STS primers for D4S1593，D4S1562，D4S2946，D4S1525， D3S1542， D3S3681, D3S3031, and D3S3508 obtained from Invitrogen (Carlsbad, CA) using standard methods [13,30]. Human papillomavirus types were identified as described earlier [29].

\section{Methylation Specific PCR (MSP) and sequencing}

Genomic DNA was treated with sodium bisulphite as described [29]. Placental DNA treated in vitro with SssI methyltransferase (New England BioLabs, Beverly, MA) and normal lymphocyte DNA converted with sodium bisulphite was used as methylated and unmethylated controls, respectively. Primers used for amplification of methylated and unmethylated promoters for each of the genes are shown in Table 1 . PCR products were run on $2 \%$ agarose gels and visualized after ethidium bromide staining. All MSP experiments were performed three times and the promoter hypermethylation was considered positive only when confirmed twice. MSP products were either directly sequenced or sub-cloned into pCR2.1-TOPO (Invitrogen) followed by sequencing multiple clones using primers common to both methylated and unmethylated templates (Table 1).

\section{Drug treatment}

Cells in culture were treated with 5 or $10 \mu \mathrm{M}$ of 5 -Aza2'deoxycytidine (5-aza-CdR) for 5 to 10 days and 100$500 \mathrm{nM}$ of Trichostatin A (TSA) for 24 hours as described [29].

\section{RT-PCR analysis}

Total RNA isolated from treated and untreated cell lines, tumor tissues, and eight normal cervix uteri (three obtained from different commercial sources and five from hysterectomy specimens) was reverse transcribed as described [29]. A multiplex semi-quantitative analysis of gene expression was performed in replicate in three independent experiments as described [29]. A given gene was considered down regulated in a tumor when the level of mRNA was less than two standard deviations, except for ROBO1 in untreated cells, of the values obtained from the normal cervix. Primers used in the present study are shown in Table 1.

\section{Statistical analysis}

Statistical analysis was performed using a Chi-square test.

\section{Competing interests}

The author(s) declare that they have no competing interests.

\section{Authors' contributions}

GN carried out all molecular genetic studies. CG participated in the MSP, cloning and sequencing. HA-P, AMK, AS, MD, MM, BP participated in collection of tissues, clinical information, and critical reading of the manuscript. VM conceived the study, participated in its design and coordination and draft of the manuscript. All authors read and approved the final manuscript.

\section{Acknowledgements}

This work was supported by the grant CA095647 from National Institutes of Health. H.A-P was supported by a grant (No. 2101-04-021-99) from Colciencias (Colombia).

\section{References}

I. Hogg R, Friedlander M: Role of systemic chemotherapy in metastatic cervical cancer. Expert Rev Anticancer Ther 2003, 3:234-240.

2. Steeg PS: Metastasis suppressors alter the signal transduction of cancer cells. Nat Rev Cancer 2003, 3:55-63.

3. Balkwill F: Cancer and the chemokine network. Nat Rev Cancer 2004, 4:540-550.

4. Guan H, Zu G, Xie Y, Tang H, Johnson M, Xu X, Kevil C, Xiong WC, Elmets $\mathrm{C}$, Rao Y, Wu JY, Xu H: Neuronal repellent Slit2 inhibits dendritic cell migration and the development of immune responses. J Immunol 2003, 171:6519-6526.

5. Park KW, Morrison CM, Sorensen LK, Jones CA, Rao Y, Chien CB, Wu JY, Urness LD, Li DY: Robo4 is a vascular-specific receptor that inhibits endothelial migration. Dev Biol 2003, 26 I:25 I-267.

6. Wong K, Park HT, Wu JY, Rao Y: Slit proteins: molecular guidance cues for cells ranging from neurons to leukocytes. Curr Opin Genet Dev 2002, I 2:583-59I.

7. Dallol A, Forgacs E, Martinez A, Sekido Y, Walker R, Kishida T, Rabbitts $P$, Maher ER, Minna JD, Latif F: Tumour specific promoter 
region methylation of the human homologue of the Drosophila Roundabout gene DUTTI (ROBOI) in human cancers. Oncogene 2002, $21: 3020-3028$.

8. Dallol A, Da Silva NF, Viacava P, Minna JD, Bieche I, Maher ER, Latif F: SLIT2, a human homologue of the Drosophila Slit2 gene, has tumor suppressor activity and is frequently inactivated in lung and breast cancers. Cancer Res 2002, 62:5874-5880.

9. Dallol A, Krex D, Hesson L, Eng C, Maher ER, Latif F: Frequent epigenetic inactivation of the SLIT2 gene in gliomas. Oncogene 2003, 22:46II-46I6.

10. Morris MR, Hesson LB, Wagner KJ, Morgan NV, Astuti D, Lees RD, Cooper WN, Lee J, Gentle D, Macdonald F, Kishida T, Grundy R, Yao M, Latif F, Maher ER: Multigene methylation analysis of Wilms tumour and adult renal cell carcinoma. Oncogene 2003, 22:6794-680I.

II. Astuti D, Da Silva NF, Dallol A, Gentle D, Martinsson T, Kogner P, Grundy R, Kishida T, Yao M, Latif F, Maher ER: SLIT2 promoter methylation analysis in neuroblastoma, Wilms' tumour and renal cell carcinoma. BrJ Cancer 2004, 90:5I5-52I.

12. Mitra AB, Murty VV, Li RG, Pratap M, Luthra UK, Chaganti RS: Allelotype analysis of cervical carcinoma. Cancer Res 1994 54:448I-4487.

13. Pulido HA, Fakruddin MJ, Chatteriee A, Esplin ED, Beleno N, Martinez $\mathrm{G}$, Posso H, Evans GA, Murty VV: Identification of a 6-cM minimal deletion at I I q23.I-23.2 and exclusion of PPP2R I B gene as a deletion target in cervical cancer. Cancer Res 2000, 60:6677-6682

14. Xian J, Aitchison A, Bobrow L, Corbett G, Pannell R, Rabbitts T, Rabbitts P: Targeted disruption of the 3 p 12 gene, Dutt I/Robol, predisposes mice to lung adenocarcinomas and lymphomas with methylation of the gene promoter. Cancer Res 2004, 64:6432-6437.

15. Herman JG, Graff JR, Myohanen S, Nelkin BD, Baylin SB: Methylation-specific PCR: a novel PCR assay for methylation status of CpG islands. Proc Natl Acad Sci U S A 1996, 93:982I-9826.

16. Dickinson RE, Dallol A, Bieche I, Krex D, Morton D, Maher ER, Latif F: Epigenetic inactivation of SLIT3 and SLITI genes in human cancers. Br J Cancer 2004, 9 I:207I-2078.

17. Issa JP: CpG island methylator phenotype in cancer. Nat Rev Cancer 2004, 4:988-993.

18. Shen L, Ahuja N, Shen Y, Habib NA, Toyota M, Rashid A, Issa JP: DNA methylation and environmental exposures in human hepatocellular carcinoma. J Natl Cancer Inst 2002, 94:755-76I.

19. Kang GH, Lee S, Kim WH, Lee HW, Kim JC, Rhyu MG, Ro JY: Epstein-barr virus-positive gastric carcinoma demonstrates frequent aberrant methylation of multiple genes and constitutes CpG island methylator phenotype-positive gastric carcinoma. Am J Pathol 2002, 160:787-794.

20. zur Hausen $\mathrm{H}$ : Papillomaviruses and cancer: from basic studies to clinical application. Nat Rev Cancer 2002, 2:342-350.

21. Etoh T, Kanai $Y$, Ushijima S, Nakagawa T, Nakanishi $Y$, Sasako M, Kitano S, Hirohashi S: Increased DNA methyltransferase I (DNMTI) protein expression correlates significantly with poorer tumor differentiation and frequent DNA hypermethylation of multiple CpG islands in gastric cancers. Am J Pathol 2004, 164:689-699.

22. Jair KW, Bachman KE, Suzuki H, Ting AH, Rhee I, Yen RW, Baylin SB, Schuebel KE: De novo CpG island methylation in human cancer cells. Cancer Res 2006, 66:682-692.

23. Prasad A, Fernandis AZ, Rao Y, Ganju RK: Slit protein-mediated inhibition of CXCR4-induced chemotactic and chemoinvasive signaling pathways in breast cancer cells. J Biol Chem 2004, 279:9115-9124.

24. Syrjanen KJ: Spontaneous evolution of intraepithelial lesions according to the grade and type of the implicated human papillomavirus (HPV). Eur J Obstet Gynecol Reprod Biol 1996, 65:45-53.

25. Marillat $\vee$, Cases $O$, Nguyen-Ba-Charvet KT, Tessier-Lavigne $M$, Sotelo C, Chedotal A: Spatiotemporal expression patterns of slit and robo genes in the rat brain. I Comp Neurol 2002, 442: I30-155.

26. Jones PA, Laird PW: Cancer epigenetics comes of age. Nat Genet 1999, 21:163-167.

27. Soprano DR, Qin P, Soprano KJ: Retinoic acid receptors and cancers. Annu Rev Nutr 2004, 24:20I-22I.
28. Karpf AR, Lasek AW, Ririe TO, Hanks AN, Grossman D, Jones DA: Limited gene activation in tumor and normal epithelial cells treated with the DNA methyltransferase inhibitor 5-aza-2'deoxycytidine. Mol Pharmacol 2004, 65:18-27.

29. Narayan G, Arias-Pulido H, Koul S, Vargas H, Zhang FF, Villella J, Schneider A, Terry MB, Mansukhani M, Murty VV: Frequent Promoter Methylation of CDHI, DAPK, RARB, and HICI Genes in Carcinoma of Cervix Uteri: Its Relationship to Clinical Outcome. Mol Cancer 2003, 2:24.

30. Narayan G, Pulido HA, Koul S, Lu XY, Harris CP, Yeh YA, Vargas H, Posso H, Terry MB, Gissmann L, Schneider A, Mansukhani M, Rao PH, Murty VV: Genetic analysis identifies putative tumor suppressor sites at 2q35-q36. I and 2q36.3-q37. I involved in cervical cancer progression. Oncogene 2003, 22:3489-3499.

31. Narayan G, Arias-Pulido H, Nandula SV, Basso K, Sugirtharaj DD, Vargas H, Mansukhani M, Villella J, Meyer L, Schneider A, Gissmann L, Durst M, Pothuri B, Murty VV: Promoter hypermethylation of FANCF: disruption of Fanconi Anemia-BRCA pathway in cervical cancer. Cancer Res 2004, 64:2994-2997.
Publish with Bio Med Central and every scientist can read your work free of charge

"BioMed Central will be the most significant development for disseminating the results of biomedical research in our lifetime. "

Sir Paul Nurse, Cancer Research UK

Your research papers will be:

- available free of charge to the entire biomedical community

- peer reviewed and published immediately upon acceptance

- cited in PubMed and archived on PubMed Central

- yours - you keep the copyright
BioMedcentral 